\title{
Early manifestation of spasticity after first stroke in the territory of the internal carotid artery. A prospective multicenter study
}

\author{
Tomas Dornaka, Maria Justanova ${ }^{b}$, Romana Konvalinkovac, Jan Muzikd, Martina Hoskovcovac, Martin Srpc, Michal Rihae, \\ Daniela Navratilova a, Pavel Otruba ${ }^{a}$, Ota Galc, Ladislav Dusek ${ }^{d}$, Robert Jech', Martin Bares ${ }^{b}$, Petr Kanovsky ${ }^{a}$
}

\begin{abstract}
Aims. The main aim of this study was to provide an estimate of the incidence and prevalence of spasticity following stroke in the internal carotid artery territory for Regional Stroke Centers in the Czech Republic. A secondary goal was to identify predictors for the development of spasticity.

Methods. In a prospective cohort study, 256 consecutive patients with clinical signs of central paresis due to a firstever stroke were examined in the acute stage. All patients had primary stroke of carotid origin and paresis of the upper and/or lower limb for longer than 7 days after stroke onset. All were examined between 7-10 days after the stroke. We evaluated the degree and pattern of paresis, spasticity using the Modified Ashworth scale and the Barthel Index, baseline characteristics and demographic data.

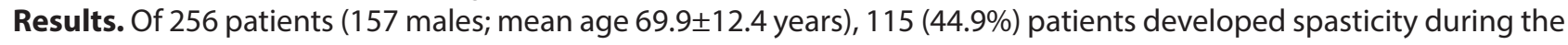
first 10 days after stroke onset. Eighty-three (32.5\%) patients presented with mild neurological deficit (modified Rankin Scale $0-2)$ and $69(27.0 \%)$ patients were bedridden.

Conclusion. Spasticity was noted in $44.9 \%$ patients with neurological deficit due to first-ever stroke in the carotid territory in the first 10 days after stroke onset. Severe spasticity was rare.
\end{abstract}

Key words: spasticity, internal carotid, stroke, ischemia, haemorrhage, anterior circulation

Received: January 25, 2018; Accepted: April 27, 2018; Available online: May 23, 2018

https://doi.org/10.5507/bp.2018.024

${ }^{a}$ Department of Neurology, Faculty of Medicine and Dentistry, Palacky University Olomouc and University Hospital Olomouc, Czech Republic ${ }^{b}$ Department of Neurology, Faculty of Medicine, Masaryk University Brno and St. Anne's University Hospital, Brno, Czech Republic 'Department of Neurology and Center of Clinical Neuroscience, First Faculty of Medicine, Charles University in Prague, Czech Republic ${ }^{d}$ Institute of Biostatistics and Analyses, Masaryk University, Brno, Czech Republic eDepartment of Rehabilitation Medicine, Central Military Hospital, Prague, Czech Republic Corresponding author:Tomas Dornak, e-mail:dornaktomas@seznam.cz

\section{INTRODUCTION}

Post-stroke spasticity (PSS) is a sensorimotor disorder characterized by a velocity-dependent increase in muscle tone with exaggerated tendon jerks ${ }^{1}$. This concept of spasticity was originally postulated by Lance ${ }^{1}$, while in epidemiological studies, spasticity is perceived as a general increase in muscle tone as a part of upper motor neuron syndrome and has been estimated to occur in $17-46 \%$ of patients 12 months after stroke ${ }^{2-6}$. High variability of findings is probably related to different methodological approaches, from telephone calls, other subjective evaluations to clinical scales. The treatment of spasticity with botulinum toxin in combination with physiotherapy is purported to improve functioning in patients with upper motor neuron syndrome ${ }^{4}$. There are statistically and clinically meaningful differences in health-related quality of life between stroke survivors with and without spasticity? Early identification, often neglected in daily clinical practice, and appropriate treatment may be difficult.

The present study follows a cohort of patients from the immediate days after stroke to assess the frequency of PSS and to identify potential risk factors for PSS development. Better understanding of the evolution of the disor- der along with identification of PSS risk factors could lead to earlier treatment and better outcomes. Knowledge about the epidemiology of PSS in Czech Stroke Centers should help with aftercare organization.

The aim of the present study was to provide a point and interval estimate of the incidence and prevalence of PSS immediately after the first stroke for the Regional Stroke Centers in the Czech Republic. The secondary goals of the study were to analyze and quantify the association between potential risk factors and the risk of spasticity and clinically significant spasticity. Pilot data on patients examined soon after stroke onset are presented. The longitudinal study (6 and 12 months) is to follow.

\section{MATERIALS AND METHODS}

\section{Ethics}

The study was conducted in accordance with the Helsinki Declaration of 1975 (as revised in 2004 and 2008), and was approved by the local ethics committee in all participating centers. Informed consent was obtained from all participants included in the study. 


\section{Patients}

Four Czech comprehensive Stroke Centers participated in this multi-center, prospective, observational, longitudinal cohort study. Web application was created with a structured questionnaire and a central repository. It was given its name Spastic Dystonia Registry (SONAR). Two hundred and fifty six consecutive patients who were admitted to any of the four participating centers in a period of two years with clinical signs of central paresis due to a first-ever stroke, were enrolled.

All patients met the following criteria: living within the regional urban territory of the given Center (must have a permanent address in this territory), first stroke of carotid origin, and the presence of motor deficit (longer than 7 days following the stroke onset). Patients with transient ischemic attack, recurrent stroke and stroke in the vertebrobasilar territory were excluded. Each patient was examined in the acute stage ( 7 to 10 days following the stroke onset, visit V1.

\section{Observed parameters}

Data were collected, including information on: demographic data, stroke risk factors, pre-event medication, localization of lesion, presence of motor deficit, presence and type of aphasia, and presence/absence of spasticity.

Demographic data included: subject initials, gender, date of birth, height, weight, hand dominance, and outcome. The presence of the following stroke risk factors was documented: coronary artery disease, atrial fibrillation, obesity, arterial hypertension, hyperlipidemia, diabetes mellitus, low physical activity, and current smoking.

The degree and pattern of paresis and muscle tone was evaluated in the contralateral elbow and wrist flexors of the upper limb, and in the knee and ankle flexors in the contralateral lower limb. Spasticity was assessed using the modified Ashworth Scale (MAS) (ref. $\left.{ }^{8}\right)$. The MAS evaluates the resistance of a relaxed limb to rapid passive stretch in 6 stages: stage 0 relates to normal or lowered muscle tone and stage 4 relates to a state in which passive movement of the affected limb is impossible. Spasticity was defined as $>1$ MAS and severe spasticity as MAS $\geq$ 3 in any of the examined muscle groups. Performance of daily living activities was measured using the Barthel index (BI) (ref. ${ }^{9}$ ). The BI is considered to be a reliable, valid, and sensitive measure of disability ${ }^{10}$. Clinical outcome was evaluated using the modified Rankin scale (mRS) (ref. ${ }^{11}$ ).

\section{Statistical analysis}

Standard descriptive statistics were used in the analysis, including the absolute and relative frequencies for categorical variables, and the mean, median, minimum, and maximum for continuous variables. The statistical significance of between-group differences was analyzed using Fisher's exact test for categorical variables. Logistic regression was used for the univariate and multivariate analysis of parameters predicting increase in muscle tone and the results were expressed as odds ratios (OR). All reported $p$-values are two-sided with $\alpha=0.05$ as the level of statistical significance; confidence intervals are given at the $95 \%$ level. Statistical analyses were computed using
Table 1. Baseline characteristics of patients $(n=256)$.

\begin{tabular}{|c|c|}
\hline Characteristics & Value (years; \%) \\
\hline \multicolumn{2}{|l|}{ Age: } \\
\hline mean; median (min-max), years & $70 ; 71(29-103)$ \\
\hline$\leq 60$ years & 22.3 \\
\hline $61-70$ years & 26.6 \\
\hline $71-80$ years & 28.5 \\
\hline $81+$ years & 22.7 \\
\hline Male gender & 61.3 \\
\hline \multicolumn{2}{|l|}{ Risk factors prior stroke: } \\
\hline arterial hypertension & 71.1 \\
\hline hyperlipidaemia & 31.3 \\
\hline diabetes mellitus & 28.5 \\
\hline current smoking & 24.2 \\
\hline coronary artery disease & 19.1 \\
\hline atrial fibrillation & 18.8 \\
\hline obesity & 18.8 \\
\hline low physical activity & 8.6 \\
\hline risk factors not available & 11.7 \\
\hline \multicolumn{2}{|l|}{ Barthel index at ward 1: } \\
\hline 100 independency & 16.4 \\
\hline 65-95 slight dependency & 29.3 \\
\hline 45-60 moderate dependency & 24.2 \\
\hline $0-40$ severe dependency & 30.1 \\
\hline \multicolumn{2}{|l|}{ Therapy one month prior stroke: } \\
\hline none & 21.9 \\
\hline antiplatelets & 25.0 \\
\hline anticoagulants & 9.0 \\
\hline antihypertensives & 66.0 \\
\hline lipid lowering drugs & 23.8 \\
\hline muscle relaxants & 0.8 \\
\hline antidepressants & 7.0 \\
\hline analgesic & 4.3 \\
\hline
\end{tabular}

IBM SPSS Statistics for Windows, Version 22.0 (IBM Corp. Armonk, NY: IBM Corp., USA).

\section{RESULTS}

The demographic data of the 256 patients are summarized in Table 1.

Eighty-three $(32.5 \%)$ patients presented with mild neurological deficit (mRS $0-2$ ) and $69(27.0 \%)$ patients were bedridden. One hundred and fifteen $(44.9 \%)$ patients developed spasticity during the first 10 days after stroke onset, as shown in Fig. 1. Most patients (34.8\%) showed only a slight increase in muscle tone (MAS 1 and 1+). More marked increase in muscle tone was observed in $8.2 \%$ of patients. Severe spasticity (MAS $\geq 3$ ) was noted in $2.0 \%$ of patients. None of the patients reached MAS 4 on visit 1. The highest prevalence and the most severe spasticity was found on the elbow flexors of the contralateral upper limb. The most affected segment on the lower limb was ankle flexors. Spasticity was statistically significantly associated with the degree of paresis; plegia vs. paresis $(56.2$ vs $36.3 \%$, resp., $P=0.001$ ). 


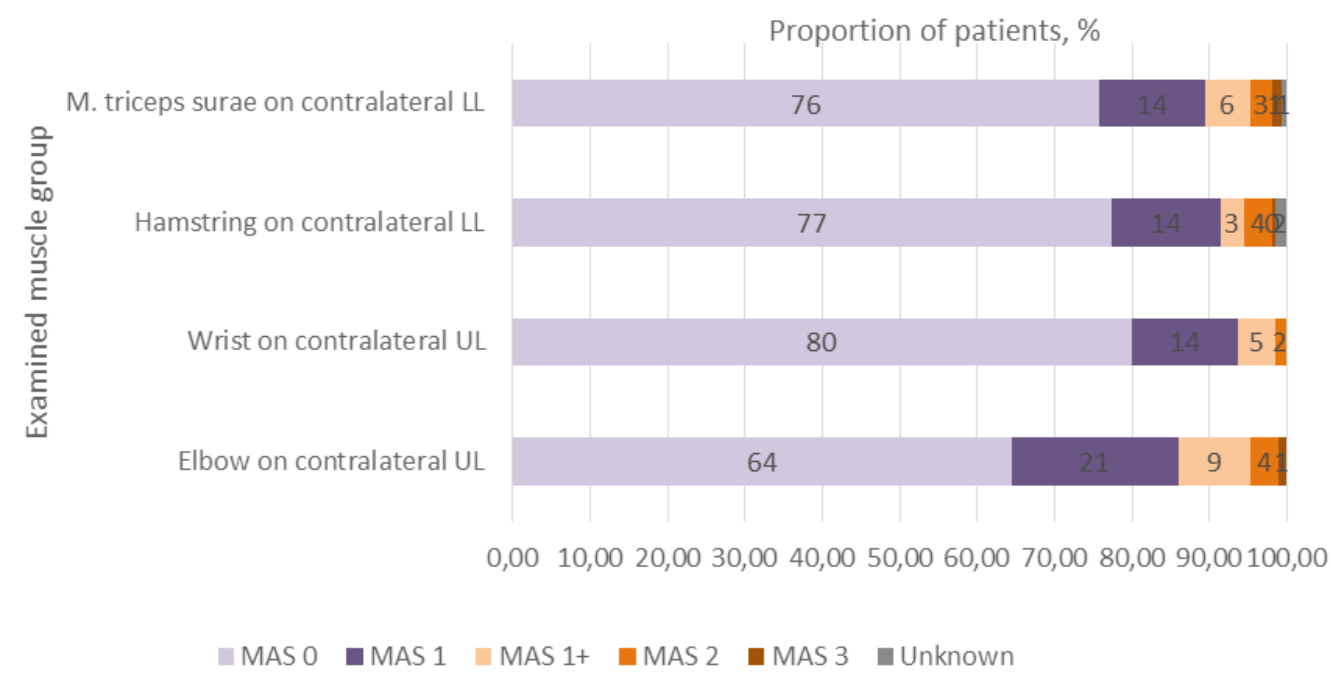

Fig. 1. Post-stroke spasticity in the cohort of examined patients at visit 1 .

UL, upper limb; LL, lower limb; MAS, modified Ashworth Scale

Based on univariate logistic regression analysis, atrial fibrillation $(\mathrm{OR}=0.44,95 \% \mathrm{CI}: 0.22-0.86 ; P=0.017)$, arterial hypertension $(\mathrm{OR}=0.55,95 \% \mathrm{CI}: 0.32-0.95$; $P=0.032)$, hyperlipidemia (OR $=0.55,95 \% \mathrm{CI}: 0.32-$ $0.95 ; P=0.032)$, and antihypertensives 1 month prior to stroke $(\mathrm{OR}=0.46,95 \% \mathrm{CI}: 0.27-0.78 ; P=0.004)$ were identified as statistically significant negative predictors for the development of spasticity, as presented in Table 2. However, stepwise binary logistic regression analysis identified no significant independent predictor of spasticity development.

\section{DISCUSSION}

In this prospective, multi-centerstudy, we are investigating a large cohort of acute stroke patients in the territory of the middle carotid artery. The study population was restricted to first stroke patients with motor deficit (limb paresis) present longer than 7 days after the stroke onset, independent of stroke origin and severity. Data from the first evaluation visit (7-10 days after stroke) were analyzed to give a pilot overview on the prevalence of PSS.

Table 2. Results of binary logistic regression analysis (unadjusted OR) - dependent variable presence of spasticity.

\begin{tabular}{lccc}
\hline Stroke risk factor & OR & $95 \%$ CI & $P$ \\
\hline Gender & 1.10 & $0.67-1.83$ & 0.704 \\
Age ( $\geq 70$ years / 71 $\geq$ years) & 1.08 & $0.66-1.76$ & 0.772 \\
Stroke risk factors & & & 0.337 \\
Coronary artery disease & 0.73 & $0.39-1.38$ & $\mathbf{0 . 0 1 7}$ \\
Atrial fibrillation & $\mathbf{0 . 4 4}$ & $\mathbf{0 . 2 2 - 0 . 8 6}$ & 0.433 \\
Obesity & 1.29 & $0.69-2.41$ & 0.529 \\
Smoking history & 1.20 & $0.68-2.13$ & $\mathbf{0 . 0 3 2}$ \\
Arterial hypertension & $\mathbf{0 . 5 5}$ & $\mathbf{0 . 3 2 - 0 . 9 5}$ & 0.108 \\
Hyperlipidaemia & $\mathbf{0 . 5 5}$ & $\mathbf{0 . 3 2}-\mathbf{0 . 9 5}$ & 0.401 \\
Diabetes mellitus II & 0.63 & $0.36-1.11$ & $0.27-1.68$ \\
Low physical activity & 0.68 & & 0.425 \\
Treatment 1 month prior stroke & & $0.45-1.41$ & 0.064 \\
Antiplatelet drugs & 0.79 & $0.15-1.06$ & $\mathbf{0 . 0 0 4}$ \\
Anticoagulants & 0.40 & $\mathbf{0 . 2 7 - 0 . 7 8}$ & 0.316 \\
Antihypertensives & $\mathbf{0 . 4 6}$ & $0.41-1.33$ & 0.594 \\
Lipid lowering drugs & 0.74 & $0.29-2.04$ & 0.514 \\
Antidepressants & 0.77 & $0.45-5.04$ & \\
\multicolumn{1}{l}{ Analgesics } & 1.50 & & \\
\hline
\end{tabular}

CI: confidence interval, OR: odds ratio 
In previously published studies, the prevalence of PSS ranged from $16-42.6 \%$ in cohorts of $83-328$ patients $^{5,6,12,13}$. The reexamination rate was from $38 \%$, in a study by Watkins et al., to $86 \%$ in a study by Lundström et al. ${ }^{5,6}$. These studies did not differentiate between initial motor and non-motor strokes in terms of the prevalence of PSS, and they included patients with intracerebral hemorrhages. Thus, a direct comparison to our data is not feasible. The lower prevalence of spasticity in comparison to the present study might be due to the smaller number of patients included. In addition, it is not clear from the study design whether only ambulatory patients were reexamined in the study by Watkins et al, which would potentially underestimate the prevalence rate of PSS (ref. ${ }^{5}$ ). Although spasticity at day 10 is significantly associated with 12 month PSS (ref. ${ }^{14}$ ), normalization of muscle tone may occur during longer follow-up care, leading to lower prevalence, as demonstrated in previously published studies ${ }^{12,14,15}$.

The number of patients who had developed spasticity 7 to 10 days after stroke onset in our study might increase over time as spasticity is caused not only by damage to the neural components but also arises in response to adaptive features such as intrinsic changes in muscle ${ }^{16,17}$. The degree of severe spasticity was low, showing MAS $\geq 3$ in $2.0 \%$. The lower rate of clinically relevant spasticity (MAS $\geq 2$ ) was apparently due to the early investigation of patients in the first evaluation visit. In contrast to a study published by Urban et al, the highest prevalence and the most severe spasticity was found on the elbow of the contralateral upper $\operatorname{limb}^{3}$.

As described by Wissel et al. ${ }^{13}$, patients who initially showed no signs of increase in muscle tone can develop spasticity during longer follow up. Few studies have dealt with the temporal evolution of spasticity after stroke. Spasticity seems to be rarely apparent during the first month following stroke. It reaches a peak 1-3 months after stroke ${ }^{18-22}$.

In line with the results of previously published studies, no stroke risk factors were identified with multivariate logistic regression analysis ${ }^{4,13,21-23}$. It is not surprising that the classical risk factors for stroke did not emerge as independent predictors of PSS, given the lack of an obvious plausible biological link. In the present study, the degree of paresis was closely related to risk and the degree of spasticity $(P<0.001)$. The more severe paresis and the more muscle group involved, the higher risk and greater degree of spasticity is to be $\operatorname{seen}^{4,13,21-23}$.

The present study has some limitations. Only pilot data are presented; data from longer (6 and 12 month) follow-up visits will be needed to verify the results. A greater emphasis on reexamination will be needed in order to minimize the loss of patients to follow-up care. Performance of daily living activities was measured solely using the Barthel index and modified Rankin scale, omitting other scales ${ }^{9}$. The Barthel index has demonstrated a high interrater reliability $(0.95)$ and test-retest reliability (0.89) as well as high correlations (0.74-0.8) with other measures of physical disability ${ }^{21}$. It is a simple protocol leading to answering the basic question, what is the preva- lence of spasticity after a first stroke in carotid territory. The modified Ashworth Scale does not differentiate whether the increase in resistance is a result of reflex hyperexcitability, biomechanical changes in soft tissues, or both, and it is not a metric measure of spasticity. However, it is easy to apply in different settings, is frequently used, and has relatively good intra rater reliability ${ }^{8}$.

\section{CONSLUSION}

In conclusion, spasticity during the first 10 days after stroke onset is common in patients with neurological deficits due to first-ever stroke. Severe early post-stroke spasticity is rare. This knowledge should encourage physicians to examine patients for spasticity early after stroke as well as to help with aftercare management of such patients.

Acknowledgement: This study was conducted on an academic basis and was partially supported by the Czech health research council of the Ministry of Health of the Czech Republic no. 15-31921A; Ministry of Health of the Czech Republic MH CZ - DRO (FNOL, 00098892)2016 and by a grant from the Internal Grant Agency of Palacky University IGA UP LF-2016-017 and IGA_ LF_2017_024.

Author contributions: RJ, MB, PK: designed the original protocol of the SONAR study; TD, MJ, RK, MR: led the recruitment of subjects in participating centres; $\mathrm{MH}, \mathrm{MS}$, DN, PO, OG: participated on the recruitment of subjects and clinical assessments; JM, LD: created the original database and performed the statistical analysis; TD: has written the first draft of manuscript.

Conflicts of interest statement: Robert Jechand, Petr Kanovsky received hororaria/consultancies from Ipsen, Allergan. Martin Bares received honoraria from Ipsen. The rest of authors have nothing to declare as possible conflict of interest.

\section{REFERENCES}

1. Lance JW. Symposium synopsis. In: Feldman RG; Young RR; Koella WP; CIBA-GEIGY Corporation. Spasticity, disordered motor control. Miami, FL: Year Book Medical Publishers; 1980. p. 485-494.

2. Opheim A, Danielsson A, Alt Murphy M, Persson HC, Sunnerhagen KS. Upper-limb spasticity during the first year after stroke: stroke arm longitudinal study at the University of Gothenburg. Am J Phys Med Rehabil 2014;93:884-6.

3. Urban PP, Wolf T, Uebele M, Marx JJ, Vogt T, Stoeter P, Bauermann T, Weibrich C, Vucurevic GD, Schneider A, Wissel J. Occurrence and clinical predictors of spasticity after ischemic stroke. Stroke 2010;41:2016-20.

4. Sommerfeld DK, Gripenstedt U, Welmer AK. Spasticity after stroke: an overview of prevalence, test instruments, and treatments. Am J Phys Med Rehabil 2012;91:814-20.

5. Watkins CL, Leathley MJ, Gregson JM, Moore AP, Smith TL, Sharma AK. Prevalence of spasticity post stroke. ClinRehabil 2002;16:515-22.

6. Lundström E, Terént A, Borg J. Prevalence of disabling spasticity 1 year after first-ever stroke. Eur J Neurol 2008;15:533-9.

7. Gillard PJ, Sucharew H, Kleindorfer D, Belagaje S, Varon S, Alwell K, Moomaw CJ, Woo D, Khatri P, Flaherty ML, Adeoye O, Ferioli S, Kissela B. The negative impact of spasticity on the health-related quality of life of stroke survivors: a longitudinal cohort study. Health Qual Life Outcomes 2015;13:159. 
8. Bohannon RW, Smith MB. Interrater reliability of a modified Ashworth scale of muscle spasticity. PhysTher 1987;67:206-7.

9. Shah S, Vanclay F, Cooper B. Improving the sensitivity of the Barthel Index for stroke rehabilitation. J ClinEpidemiol 1989;42:703-9.

10. Collin C, Wade DT, Davies S, Horne V. The Barthel ADL Index: a reliability study. IntDisabil Stud 1988;10:61-3.

11. van Swieten JC, Koudstaal PJ, Visser MC, Schouten HJ, van Gijn J. Interobserver agreement for the assessment of handicap in stroke patients. Stroke 1988;19:604-7.

12. Sommerfeld DK, Eek EU, Svensson AK, Holmqvist LW, von Arbin MH. Spasticity after stroke: its occurrence and association with motor impairments and activity limitations. Stroke 2004;35:134-9.

13. Wissel J, Schelosky LD, Scott J, Christe W, Faiss JH, Mueller J. Early development of spasticity following stroke: a prospective, observational trial. J Neurol 2010;257:1067-72.

14. Opheim A, Danielsson A, Alt Murphy M, Persson HC, Sunnerhagen KS. Early prediction of long-term upper limb spasticity after stroke: part of the SALGOT study. Neurology 2015;85:873-80.

15. Lundström E, Smits A, Terént A, Borg J. Time-course and determinants of spasticity during the first six months following first-ever stroke. J Rehabil Med 2010;42:296-301.
16. O'Dwyer NJ, Ada L, Neilson PD. Spasticity and muscle contracture following stroke. Brain 1996;1 19:1737-49.

17. Vattanasilp W, Ada L, Crosbie J. Contribution of thixotropy, spasticity, and contracture to ankle stiffness after stroke. J NeurolNeurosurg Psychiatry 2000;69:34-9.

18. Crone C, Johnsen LL, Biering-Sørensen F, Nielsen JB. Appearance of reciprocal facilitation of ankle extensors from ankle flexors in patients with stroke or spinal cord injury. Brain 2003;126:495-507.

19. Ju MS, Chen JJ, Lee HM, Lin TS, Lin CC, Huang YZ. Time-course analysis of stretch reflexes in hemiparetic subjects using an on-line spasticity measurement system. J Electromyogr Kinesiol 2000;10:1-14.

20. Thilmann AF, Fellows SJ, Garms E. The mechanism of spastic muscle hypertonus. Variation in reflex gain over the time course of spasticity. Brain 1991;114:233-44.

21. O'Sullivan, SB; Schmitz, TJ. Physical Rehabilitation, 5th Ed. Philadelphia, F.A.; 2007.

22. Kong KH, Lee J, Chua KS. Occurrence and temporal evolution of upper limb spasticity in stroke patients admitted to a rehabilitation unit. Arch Phys Med Rehabil 2012;93:143-8

23. Leathley MJ, Gregson JM, Moore AP, Smith TL, Sharma AK, Watkins $\mathrm{CL}$. Predicting spasticity after stroke in those surviving to 12 months. ClinRehabil 2004;18:438-43. 